\title{
Peer Networks, Generational Status and Achievement of American Adolescents
}

\author{
Igor Ryabov \\ The University of Texas-Pan American \\ 1201 W. University Drive, Edinburg, TX 78539-2999, USA
}

Tel: 1-956-665-7874 E-mail: ryabovi@utpa.edu

Received: October 10, 2011

Accepted: October 31, $2011 \quad$ Published: December 30, 2011

doi:10.5539/jedp.v1n1p105

URL: http://dx.doi.org/10.5539/jedp.v1n1p105

\begin{abstract}
The present study attempted to address the gap in the literature by focusing on peer network density and heterogeneity and average achievement of peers. These outcome variables were academic achievement and attainment, measured as Grade Point Average (GPA) and odds of having college education, respectively. The independent variables also included immigrant generational status, family social capital measures, and SES. The study used multilevel, hierarchical modeling to estimate the aforementioned effects. The sample was drawn from the National Longitudinal Study of Adolescent Health (Waves I and III; N=14,322). Results revealed that structural characteristic of peer networks, such as density and heterogeneity, were associated with academic outcomes, regardless of generational status. Furthermore, the relationship between the peer network variables peer network density, heterogeneity and average peer achievement - and academic outcomes was stronger for immigrant youths than for native youths. Of the aforementioned measures, average peer achievement had the strongest effect on both achievement and attainment.
\end{abstract}

Keywords: Academic achievement and attainment, Peer networks, Social capital, Immigrant assimilation

\section{Introduction}

Numerous studies have examined the many reasons why immigrant youths under- or overachieve in school in comparison to native youths (e.g., Aldous, 2006; Bankston, 2004; Fuligni, Witkow, \& Garcia, 2005; Morgan \& Sørensen, 1999) (Note 1). Little is known, however, about peer network characteristics and the way in which they can mediate the influence of school effects on academic achievement of immigrant adolescents. Only recently has academic interest turned to these issues (Kao \& Rutherford, 2007). Yet, those few studies that have attempted to explore this uncharted terrain have limited generalizability due to their exclusive attention to Hispanics and the Southwest (e.g., Ryabov \& Van Hook, 2007; Stanton-Salazar \& Spino, 2001). Moreover, on a methodological plane, empirical research dedicated to the investigation of school context factors related to educational performance has failed to differentiate peer effects from school composition effects. Hence, although peer effects on educational outcomes have been addressed by some of the most influential works in the sociology of education (Bankston \& Caldas 2002; Coleman et al., 1961; Opdenakker \& Van Damme, 2001; Mouw \& Entwisle, 2006; Rumberger \& Palardy, 2000), the characteristics of peer networks that may be conducive to educational achievement and attainment remain largely ignored.

Building on social capital framework, this paper sought to elucidate the way immigrant generational status affects academic outcomes through the effects of social capital present in peer networks as well as in families. Specifically, attempt has been made to model academic achievement and attainment as a function of peer network characteristics (density and heterogeneity) and average achievement of peer network. Note that the present study focuses on two educational outcomes - achievement and attainment. Generally speaking, educational achievement is intended to estimate how much students actually learn, while educational attainment, usually, denotes years/months of school completed. Achievement and attainment describe different aspects of educational outcomes. Educational achievement captures an extent of adaptation to a particular school, class, teacher, etc., while educational attainment to a great extent determines labor market opportunities. The data also allowed for controlling school-level factors - socioeconomic composition of schools, percentage of immigrant youths and sector (private vs. public). All these variables are known from the literature to influence between-school differences in academic outcomes (Opdenakker \& Van Damme, 2001; Ryabov \& Van Hook, 
2007; Raudenbush \& Bryk, 2002). The independent variables also included immigrant generational status, family structure, measures of quality of parent-child relationships (expectations, interactions and support), and SES (family income, parents' education and occupational prestige).

The present study had been also empirically motivated by the availability of a large representative data - the National Longitudinal Study of Adolescent Health (Add Health). Unlike most of the existing data sources that only survey the academic achievement of adolescent respondents, and not their parents or members of their peer network, the Add Health incorporated information from each of these three sources - the adolescent, parents, and friends - to provide a complete account of all possible social interactions among them. These data allowed the examination of the relative influences of peer group factors and family context differentially by generational status. By using Waves 1 and 3 of the Add Health, the study's findings provided an insight into about the causal order of the relationship between the key variables. Particularly, the study investigated how peer and family social capital measured in Wave I influenced educational attainment in Wave III while controlling for educational achievement and other individual-level factors in Wave I.

\section{Theoretical Background}

Social capital is the central theoretical concept in the present study. Pierre Bourdieu, one of the founders of social capital theory, defined the concept as "the aggregate of the actual or potential resources which are linked to... membership in a group - which provides each of its members with the backing of the collectivity owned capital" (1986: 249). Bourdieu's work (e.g., Bourdieu, 1984, 1986; Bourdieu \& Wacquant, 1992) has also been credited with the introduction the "network view" of social capital. This view was further elaborated by Granovetter (1983) who introduced such notions as bridging and bonding social capital. These types of social capital are distinguished on the basis of the number of social ties to an out-group relative to the total number of ties to in-group and out-group members. In Granovetter's terms (1983) bridging social capital is based on week ties - social ties to out-group members. These ties enable an actor to bridge between dissimilar individuals. In contrast, the bonding social capital is based on strong ties - social ties to in-group members. These ties reflect intensity of reciprocal social exchange.

The Granovetter's views have been extensively adopted to the studies of immigrant groups and their assimilation into American society (e.g., Kao \& Rutherford, 2007; Rong, \& Brown, 2001). Moreover, they were of use in the context of the present study, while examining the influence of social capital on American adolescents' academic achievement and attainment differentially by immigrant status. In examining the influence of social capital on American adolescents' academic achievement, this study considers whether adolescents' cohesive educationally oriented peer networks (representing bonding social capital) impact student's educational success differently than their open peer networks (representing bridging social capital). Theoretically, weak and strong ties provide immigrant American adolescents with social capital of different quality. It has been shown that weak ties endorse cross-group integration (e.g., Ogbu \& Simons, 1998; Stanton-Salazar \& Spino, 2001) and, therefore, should assist immigrant students in adopting patterns of educational achievement close to those of the natives. Quite the opposite, strong ties to co-ethnics foster social cohesion and social support and will allow immigrant youths to maintain the level of achievement typical to their group. Since strong ties are usually characterized as dense and homogeneous (Lin, 2001), density and heterogeneity (the opposite of homogeneity) of peer network are the key independent variables of this study.

\section{Research Hypotheses}

Based on the above literature, the main hypothesis tested the differences by nativity status in the amount and kinds of peer social capital (bonding vs. bridging) that are conductive to adolescent educational progress. This is expected because a number of studies show that immigrant youths are less vulnerable to the peer influences than native youths (Rong \& Brown, 2001; White \& Glick, 2000). With respect to network structure, two alternative scenarios were explored. First, if immigrant youths valued more bonding rather than bridging social capital, then there would be a strong and positive association between their educational outcomes and homogeneity and density of their peer networks. Should this be the case, family-based social capital would have a positive effect on immigrant youths' educational outcomes and would account for some generational differences in educational achievement and attainment. Second, if immigrant youths valued more bridging rather than bonding social capital, then homogeneity and density of peer networks would be negatively associated with educational outcomes. In this case, an association between educational outcomes and family-based social capital would be unlikely. As regards the amount of social capital available to individual students, a direct relationship between individual students' achievement and attainment and his or her peers' achievement was hypothesized.

Given that the Add Health data allowed for investigating a number of possible determinants of American 
adolescents' academic achievement and attainment, the present study tested hypotheses of secondary significance. This is primarily in reference to the factors associated with the family-based social capital, such as family structure and quality of parent-child relationships. Because the academic success of most students is largely determined by family influences (Cook et al., 2009; Crosnoe, 2000; Faircloth \& Hamm, 2005), it was hypothesized that these factors would have a strong influence on adolescent achievement and attainment. Particularly, adolescents in two-parent families as well as those whose parents were actively involved in their lives were expected to have better academic outcomes. It was also hypothesized that achievement and attainment varied by generational status even after controlling for other individual-level factors.

\section{Methodology}

\subsection{Sample}

The study sample was drawn from the National Longitudinal Study of Adolescent Health (a.k.a. the Add Health). Details regarding the methodology of the survey were described by Bearman, Jones, \& Udry (1997). In brief, this survey used a multistage probability sample design, had a response rate of $79 \%$, and resulted in a nationally representative sample of adolescents between the ages of 12 and 21 years. All students registered at participating schools were eligible for selection. The Add Health sample included all former students, including those who had not finished the school. Each school was stratified by sex and grade, with students randomly chosen within each stratum. During Wave 1 all students present in the 132 selected schools the day the self-administered questionnaire was conducted were surveyed. A subset of students was randomly selected from the 132 schools for in-home interviews, as was a parent or parent-figure. Since educational achievement, one of the dependent variables, contained 14 cases with missing values, these cases were excluded from the further analyses (final $\mathrm{N}=$ 14,322 from 129 schools). Table 1 reveals that the sample's sex ratio is balanced with approximately equal proportions of male and female students. The average age of Wave I respondents in the summer of 1995 was 15 years. Approximately $65 \%$ were non-Hispanic white, 16\% African-American, $14 \%$ Hispanic, and 5\% Asian.

\section{Insert Table 1}

Missing Values. It should be noted that missing values for all variables were imputed using the Markov Chain Monte Carlo technique (for more information on Monte-Carlo imputation see Rubin 1987, 1996). This imputation technique yielded successive simulations of the distribution of missing values, conditioned on both observed data and assuming that the data are missing at random. This imputation was carried out via a procedure (Proc MI) in the SAS software.

\subsection{Measures}

Dependent Variables. Educational achievement in Wave I and educational attainment in Wave III were the dependent variables of the present study. Grade Point Average (GPA) was used as a measure of educational achievement. The indicator of educational attainment called from the Wave III results, which helps to address concerns about causal ordering. Respondents, who are young adults in Wave III (ages 18-26), were asked about the highest grade or year of regular school they have completed. Their answers provided an indication of whether the student dropped out of school, went to college and so on. The attainment is cohort-specific. For example, a 18 -year-old will not likely have a college degree at the time when Wave III data were collected. Similarly, the Add Health measure is censored from below, as only few respondents reported not having completed the $6^{\text {th }}$ grade. Therefore, it makes sense to transform the original Add Health attainment variable into a binary outcome ("entering college" $=1$ or "not entering college" $=0$ ). The choice of entering college as the threshold for attainment was guided by the following: first, going to college is among the most important transitions, and, second, odds of attending college are lower for immigrants than for natives (Portes \& Rumbaut, 2001; Rong,, \& Brown, 2001).

Independent Measures. Three dimensions of the peer social capital - relative density, racial/ethnic heterogeneity and average achievement of peer network, proxied by GPA in Wave I - were used as independent measures. All these measures were created on the basis of the friend nominations. Students were asked to list their best friends (including their romantic partners).(Note 2) For each participating school, the Add Health created a roster which enabled students to find their friends in their school and a sister school.

The first measure, peer network density, represents the degree to which actors know each other. The network density can be expressed mathematically as a ratio of observed ties in the network to all possible ties in the total friendship network. It can be expressed as follows: 


$$
\text { Heterogene ity }=1-\sum_{1}^{4}\left(\frac{R_{C}}{4 * I}\right)
$$

$\mathrm{R}$ is the number of peers in a network belonging to a certain $C$ race/ethnic category, $I$ is the total number of peers in a peer network, and 4 is the number of race/ethnic categories used in the analyses (i.e., African-American, Asian, Latino, and non-Hispanic white). Note that heterogeneity ranges from 0 (i.e., the situation when all members of a network share the same race/ethnicity) to 1 (i.e., the situation when all four race/ethnic categories are equally represented in a network). Finally, average GPA in an individual student's network was calculated as an arithmetic mean of the GPA scores of his/her friends.

Given the focus of this study on immigrant assimilation, one of the key independent variables was generational status. The concept and its operationalizion used in the present study were drawn from assimilation studies (Fuligni et al., 2005; Hirschman, 2001; Portes \& Rumbaut, 2001). All adolescents were divided into five categories: first-, 1.5-, second-, 2.5-, and third- and higher-generation. Those born outside the United States were counted as foreign-born children of immigrants unless they were born in a foreign country of American parents. They immigrated to the U.S. as children. Because prior studies (e.g., Tillman, Guo, \& Harris, 2006; Oropesa \& Landale, 1997) showed that arrival by age six is associated with a markedly different schooling, six-year threshold was chosen to distinguish 1 and 1.5 generations. Foreign-born respondents who were 6 years of age or older at the time of the interview are coded as first generation and those who were less than that age as first-and-half generation. Furthermore, the second generation - those with two foreign-born parents - was distinguished from generation 2.5 - those with one native-born parent and one foreign-born parent. The thirdand higher generation group consisted of cases where both adolescents and their parents were U.S.-born. Adolescents who had immigrants among their grandparents or great grandparents were coded as the "third-plus" generation. Because the immigration experience of their grandparents did not bear any significant effect on their cognitive development, this category was not differentiated from the native population. As shown in Table 1, generation 3+ was the largest among generational status groups, with more than $60 \%$ of all adolescents.

Control Measures. The effects of socioeconomic status were controlled at the individual and at the school levels. Family income, parents' education and occupational prestige are included to measure economic, social, and educational characteristics of the student bodies' families. Because the jobs available to immigrants often do not match up with their educational attainment, it was important for the purposes of the present study to analyze them separately at the individual level. At the school level, however, these variables were strongly related $($ Cronbach's alpha $=0.90)$. Consequently, the standardized scores of income, education and occupational prestige of students' parents were aggregated to create a school-level SES variable. The measure that accounts for the concentration of immigrant youths in school was computed by aggregating person-count variable of immigrant generations 1.0 through 2.5 by school. Another variables controlled at the school level was the sector (private/public).

The individual-level controls included gender, age, and ethnicity. Ethnicity was defined using the self-reported ethnic identity by a set of dummy variables: Non-Hispanic White, Hispanic, Asian, and African-American. For most of my analyses, white adolescents of Non-Hispanic heritage were treated as the reference group. Gender is a dummy variable with female serving as the reference category. Age was measured in complete years at the time of interview.

Another group of independent variables was constructed to assess the impact of family social capital on academic outcomes. Following Coleman (1988) and Teachman, Paasch, \& Carver (1996), general (e.g., family structure) and specific (e.g., relationships with parents) forms of family social capital were operationalized. Two-parent family (reference) was contrasted with single-parent families, and non-parent families. The number of siblings living in the household is also included as a control measure. The measures of family process parents' educational expectations, parent-child interactions and family social support - are constructed as average scores of its components. They were drawn from the study of Bankston \& Zhou (2002) that used the Add Health data. The measure of parent-child interactions was constructed from ten items that inquired into the activities that parents and adolescents had held together over the past four week period. The activities undertaken by the adolescent and at least one parent were then summed to form the scale with the reliability index (Cronbach's alpha) of 0.73 . The scale monitoring parents' educational expectations was created from two items asked separately about mother's and father's expectations. Respondents were asked how disappointed each parent would be if they failed to graduate from college and high school. Responses ranged from low (1) to high disappointment (5). The reliability coefficient (Cronbach's alpha) for these items was 0.81 . Responses were 
averaged to create an index. Family social support was constructed by summing adolescents' affirmative responses to four items. These items indicate whether an adolescent felt that their parents/family (1) cared about them; (2) understood them; (3) had fun together; and (4) paid attention to them. The family social support scale had a Cronbach's alpha of 0.78 .

\subsection{Analytical Plan}

Multilevel modeling was an analytical technique employed in the present study for multivariate analyses. The Hierarchical Linear Models (HLM) was used as an appropriate statistical package for multilevel analyses in this study. Treating students as level-one units and schools as level-two units, the research model could be conceptualized as a two-level model. As a HLM stipulation, all individual-level continuous variables were grand-mean centered in order to avoid multicollinearity between individual and school characteristics.

The HLM was appropriate for at least three reasons. First, to address the research questions, the relationship between educational outcomes and an individual student's SES must have been isolated from the relationship between educational outcomes and the school-level SES. Second, preliminary analyses suggested that between-school differences were a source of observed differences in college enrollment. An analysis of the intraclass correlations (not shown) revealed that 10.7 and $12.3 \%$ of the variance in educational achievement and attainment, correspondingly, was accounted for by differences in the characteristics of the schools that students attend. Finally, the HLM was appropriate from the statistical point of view. Failing to account for different units of analysis (i.e., student and school) could lead to aggregation bias, miscalculation of standard errors, and heterogeneity of regression (Raudenbush \& Bryk, 2002). The HLM also addressed the design effects that were inherent in the Add Health dataset, which utilized a sampling frame that first sampled schools and then sampled students within the schools (Thomas \& Heck, 2001).

The HLM models presented here included the focus school-level predictors of academic achievement and attainment, the estimation of a random slope for generational status, family social capital, and the individual-level controls. A baseline model (model 1) that included only generational status was estimated first. Model 2 added the individual- and school-level controls, including ethnicity, parents' income, education, and occupational prestige, age and gender. It tested whether immigrant generation effects held after controlling for SES and other individual-level measures. Model 3 incorporated the family-related predictors into the analysis and tested whether family social capital helped explain any association between generational status and achievement and attainment. Models 4, 5 and 6 added, respectively, average achievement, density and heterogeneity of peer network. Observe that these variables were not included altogether in one model because they were strongly correlated with each other (the covariance matrix and correlations are not shown for parsimony). Thus models 4,5 and 6 each added one more predictor to model 3 . It is worth noting that models 4 , 5,6 were nested within model 3 , while models 3 and 2 were nested, respectively, within models 2 and 1 . In order to test whether the nested models showed improved fit over the baseline models, the test similar to the nested F-test for OLS regression models was utilized. The test was based on the Bayesian information criterion (for more on Bayesian statistics see Raudenbush \& Bryk (2002)). It had a chi-square distribution with degrees of freedom equal to the difference in the number of parameters estimated in the models.

The regression models presented in Tables 2 and 3 contained a random intercept for educational achievement and attainment, respectfully. The predictors of achievement were estimated first and then the very same procedure was repeated for the predictors of attainment. The exception was that Wave I GPA was included as a control variable in Models 6, 7, and 8 of Table 3 while age at Wave I interview was dropped because change in GPA over time measured in these models already incorporates the age/time aspect. Because models of Tables 2 and 3 are nearly identical, it makes sense to review the analyses presented in these tables concurrently (see below).

\section{Results}

The analyses presented in Tables 2 and 3 show that the native adolescents did not have an advantage in academic achievement and attainment over immigrant generations. Whether controlling for individual- and school-level variables or not, the multilevel results were consistent: children of immigrants and particularly those who were immigrants themselves had an educational advantage over the native youths. The 1.5 generation had by far the highest educational achievement and attainment in all regression models. (Note 3 )

\section{Insert Table 2}

Insert Table 3

Tables 2 and 3 show that the regression coefficients for all immigrant generations, except one for the 
second-and-half generation, were positive, thus indicating a considerable "immigrant advantage" over the natives. That said, nevertheless, achievement (see Table 2) and attainment (see Table 3) of generation 2.5 did not differ significantly from those of native adolescents. Consequently, those youths who had both parents born outside of the U.S. shared the "immigrant advantage" over the natives. In the case of generation 1.5, this advantage seems to be a cumulative effect of having immigrant parents and arriving in this country before the school age. The earlier arrival explains why generation 1, also being foreign-born as generation 1.5 but unlike them coming to the U.S. at 6 years of age or older, had a lower educational achievement and attainment than generation 1.5. Thus, educational attainment was affected by both factors that defined immigrant generation in this study: age at arrival and immigrant status of parents.

It should be also noted that adding the individual- and school-level controls modified the baseline generation coefficients, thus suggesting that school characteristics and demographic influences were independent of the social capital (both family- and peer-based) effects. Particularly, in Tables 2 and 3, the generational status coefficients increased in model 2 as compared to model 1 (baseline model). Notice that model 2 added schooland individual-level controls among which there was a number of significant effects. In Table 2 these included school sector (private), African-American and Hispanic ethnicity, family income, parents' educational attainment, age and sex. In Table 3 all control variables were significant in model 2, except age and average SES of school. Consequently, association between immigrant generation and school outcomes was stronger when the aforementioned effects were accounted for. As expected from the studies focused on school context effects, educational outcomes in private schools, on average, were better than in public schools. Turning to ethnicity effects, it is important to emphasize that Asian-American and Non-Hispanic white students performed better in school than African-Americans and Hispanics. Additionally, the SES measures had a strong effect on academic outcomes.

With regard to peer effects, average achievement of a peer network in Wave I had a positive effect on both educational achievement in Wave I and attainment in Wave III. The effects of network density and heterogeneity, however, were both insignificant. Apart from the easily observed effects of families (ethnicity, generational status, SES, and family social capital) and schools (pubic/private sector), the average achievement of a peer network in Wave I was one of the strongest predictors of academic achievement in Wave I and attainment in Wave III.(Note 4) This effect also explained some of the association between generation and achievement. Generally, the differences in achievement and attainment diminished between the generations when the average achievement of a peer network was controlled for. Further, as evidenced in models 5 and 6 of Tables 2 and 3, the lesser change in the same direction accompanied the introduction of peer network density and heterogeneity. Therefore, it was justifiable to examine the interaction effects of generational status and peer network characteristics (density and heterogeneity).

Generally, family effects differed depending on whether they were regressed on achievement or attainment. Several, but not all family-related predictors of achievement were significant. These included residing in a single-parent household, number of siblings and parents' educational expectations. In models where educational attainment was a dependent variable, all measures of family social capital, except the number of siblings, were found to be significant. As expected, living in single-parent families and number of siblings are negative predictors of attainment. Living in families headed by other relatives than parents did not have a significant impact on attainment, but it did on achievement in model 4 of Table 2, which controls for the average achievement of a peer network. This impact was, unexpectedly, positive, suggesting that the adolescents coming from non-parent (guardian) families perform better in school when peer social capital and all other factors are controlled for. It is worth mentioning that, although not all family social capital measures were significant in model 3 of both Tables 2 and 3, their addition result in model 3 being a significant improvement over model 2. It should also be noted that, after introducing the effects of the family social capital measures, the absolute values of the regression coefficients of generational status on achievement and, especially, attainment decline. This indicates a presence of certain mediating effects of family factors on academic achievement.

\section{Insert Table 4}

The interaction effects of generational status and peer network factors on educational achievement and attainment are presented in Table 4. They were all significant and positive with the exception of the interaction effect of generational status and network heterogeneity. This effect was not significant in the case of achievement and was negative in the case of attainment. The main effect of the network achievement was significant in all regression models which is consistent with the results presented in Tables 2 and 3. The main effects of network density and heterogeneity were not significant, despite the fact that some if their interaction effects mentioned above were. Thus, although average GPA of the peer network was positively associated with educational 
achievement and attainment for all youths, immigrant adolescents were predicted to have even better educational achievement and attainment than their native peers in schools where average achievement of the peer networks was higher. Similarly, network density was associated with better achievement and attainment for immigrant youths, but not for native youths. However, native adolescents were predicted to have better educational outcomes than immigrant adolescents wherever peer networks were more heterogeneous with respect to ethnicity.

\section{Discussion}

The purpose of the present study was to examine the link between academic achievement and attainment of American adolescents and structural characteristics of peer networks (density and heterogeneity) and average achievement of peers. The multilevel hierarchical analyses conducted on the National Longitudinal Study of Adolescent Health (Waves I and III) revealed that: (1) after taking into account competing influences of sociodemographic characteristics, family social capital and school context, educational achievement in Wave I and attainment in Wave III were higher among immigrant youths than native youths; (2) better educational outcomes of immigrant youths were at least in part the result of structural features of peer networks that they attend. (Note 5)

On a theoretical plane, assimilation can be constructed as a process in which the newer generations of immigrants will be less likely to rely on close-nit ties, while their social networks become less dense and homogeneous. Hence, they will be more likely to benefit from the "strength of weak ties" - that is, ties to the host society (bridging social capital). On the other hand, assimilation can be seen as a process in which the importance of close-knit ties increases with each new (bonding social capital). Out of the two dimensions of social capital embedded in peer relationships examined in this study, average academic achievement of peer network and network density were positively associated with immigrant youths' academic achievement and attainment, and network heterogeneity was negatively associated with their attainment. It is worth noting that all of these factors were less beneficial for native adolescents than for immigrant adolescents.

The main findings of this study contradict the view that "weak ties" are more important for educational advancement than "strong ties" (e.g., Granovetter, 1983; Lin, 2001). In fact, it was not bridging but bonding social ties that were found to be conducive to educational success of immigrant youths. Immigrant youths' academic outcomes are strongly and positively associated with density of their peer networks, which is not the case for native youths. In other words, those immigrant youths who attended schools with dense and homogeneous networks were more likely to have better educational outcomes than native youths. (Note 6) By the same token, this indicates that the favorable impact of bonding social capital on academic achievement and attainment appears to level off for native youths. This finding is consistent with the prior research showing that the reliance on bonding social capital improves chances of upward social mobility among immigrant groups (Fuligni et al., 2005; Rong \& Brown, 2001; Witkow \& Fuligni, 2007).

Several limitations of our study warrant noting. First, establishing causal relationships is a difficult endeavor, particularly in the case of friendship preferences, where issues of selection are a concern. Second, the Add Health school-level measures were only collected during Wave I. Although this posed no problems for my examination of achievement, it did for attainment, the information on which was collected several years after Wave I. The assumption was that school compositions had remained unchanged throughout the period under consideration. Because earlier studies have demonstrated that the composition of school districts changes slowly (Kahlenberg, 2001; Kao \& Rutherford, 2007), it is possible that the results would remain the same even with more desirable data.

In sum, this study provides important information about how various structural elements of peer networks relate to the educational assimilation of immigrant youth. While validating peers as a significant factor in adolescent academic achievement, findings suggest that educators should pay close attention to the role and functions of peer networks within broader social contexts. I fact, education is one of the few intervention points for the creation of social capital. The relationships formed at school are important for immediate social support and for linking to institutional resources.

\section{References}

Aldous, J. (2006). Family, ethnicity, and immigrant youths' educational achievements. Journal of Family Issues, 27, 1633-1667. http://dx.doi.org/10.1177/0192513X06292419

Bankston, C. L. (2004). Social capital, cultural values, immigration, and academic achievement: The host country context and contradictory consequences. Sociology of Education, 77, 176-79. 
http://dx.doi.org/10.1177/003804070407700205

Bankston, C. L., \& Caldas, S. J. (2002). A Troubled dream: The promise and failure of school desegregation in Louisiana. Nashville, TN: Vanderbilt University Press.

Bankston, C. L., \& Zhou, M. (2002). Social capital as process: The meanings and problems of a theoretical metaphor. Sociological Inquiry, 72, 285-317. http://dx.doi.org/10.1111/1475-682X.00017

Bearman, P. S., Jones, J., Udry, J. R. (1997). The National Longitudinal Study of Adolescent Health. [Online] Available: http://www.cpc.unc.edu/projects/addhealth.html (February 12, 2008).

Bourdieu, P. (1984) [1979]. Distinction: A social critique of the judgment of taste. Cambridge, MA: Harvard University Press.

Bourdieu, P. (1986). The forms of capital. In J. G. Richardson (Ed.), The handbook of theory: Research for the Sociology of Education (pp. 241-258). New York: Greenwood Press.

Bourdieu, P., \& Wacquant, L. J. D. (1992). An invitation to reflexive sociology. Chicago and London: University of Chicago Press.

Coleman, J.S. (1988). Social capital in the creation of human capital. American Journal of Sociology, 94 (Suppl.), 95-120. http://dx.doi.org/10.1086/228943

Coleman, J. S., Campbell, E. Q., Hobson, C. J., McPartland, J., Mood, A. M., Weinfeld, F. D., \& York, R. L. (1966). Equality of Educational Opportunity. Washington, DC: U.S. Government Printing Office.

Cook, E. C., Buehler, C. \& Hensen, R. (2009). Parents and peers as social influences to deter antisocial behaviour. Journal of Youth and Adolescence, 38, 1240-1252. http://dx.doi.org/10.1007/s10964-008-9348-x

Crosnoe, R. (2000). Friendships in childhood and adolescence: the life course and new directions. Social Psychology Quarterly, 63, 377-391. http://dx.doi.org/10.2307/2695847

Faircloth, B. S., \& Hamm, J. V. (2005). Sense of belonging among high school students representing 4 ethnic groups. Journal of Youth and Adolescence, 34, 293-309. http://dx.doi.org/10.1007/s10964-005-5752-7

Fuligni, A. J., Witkow, M., \& Garcia, C. (2005). Ethnic identity and the academic adjustment of adolescents from Mexican, Chinese, and European backgrounds. Developmental Psychology, 41, 799-811. http://dx.doi.org/10.1037/0012-1649.41.5.799

Granovetter, M. (1983). The strength of weak ties: a network theory revisited. Sociological Theory, 1, 201-233. http://dx.doi.org/10.2307/202051

Kao, G., \& Rutherford, L. T. (2007). Does social capital still matter? Immigrant minority disadvantage in school-specific social capital and its effects on academic achievement. Sociological Perspectives, 50, $27-52$. http://dx.doi.org/10.1525/sop.2007.50.1.27

N. Lin (2001). Social capital: A theory of social structure and action. Cambridge, UK: Cambridge University Press.

Morgan, S. L., \& Sørensen, A. B. (1999). Parental networks, social closure, and mathematics learning: A test of Coleman's social capital explanation of school effects. American Sociological Review, 64, 661-681. http://dx.doi.org/10.2307/2657368

Mouw, T., \& Entwisle, B. (2006) Residential segregation and interracial friendship in school. American Journal of Sociology, 112 (2), 394-441. http://dx.doi.org/10.1086/506415

Ogbu, J., \& Simons, H. (1998). Voluntary and involuntary minorities: A cultural-ecological theory of school performance with some implications for education. Anthropology and Education Quarterly, 29, 155-188. http://dx.doi.org/10.1525/aeq.1998.29.2.155

Opdenakker, M., \& Van Damme, J. (2001). Relationship between school composition and characteristics of school process and their effect on mathematics achievement. British Educational Research Journal, 27, 407-432. http://dx.doi.org/10.1080/01411920120071434

Oropesa, R. S., \& Landale, N. (1997). Immigrant legacies: ethnicity, generation, and children's familial and economic lives. Social Science Quarterly, 78, 399-416.

Portes, A., \& Rumbaut, R. G. (2001). Legacies: The story of the immigrant second generation. Berkeley, CA: University of California Press.

Raudenbush, S. W., \& Bryk, A. (2002). Hierarchical linear models: Applications and data analysis methods ( $2^{\text {nd }}$ 
ed.). Newbury Park, CA: Sage Publications.

Rong, X. L., \& Brown, F. (2001). The effects of immigrant generation and ethnicity on educational attainment among young African and Caribbean blacks in the United States. Harvard Educational Review, 71, 536-565.

Rubin, D. B. (1987). Multiple imputation for non-response in surveys. New York: Wiley. http://dx.doi.org/10.1002/9780470316696

Rubin, D. B. (1996). Multiple imputation after 18+ years. Journal of the American Statistical Association, 91, 473-489. http://dx.doi.org/10.2307/2291635

Rumberger, R. W., \& Palardy, G. J. (2000). Does segregation still matter? The impact of student composition on academic achievement in high school. Teachers College Record, 107, 1999-2045. http://dx.doi.org/10.1111/j.1467-9620.2005.00583.x

Ryabov, I., \& Van Hook, J. (2007). School segregation and academic achievement among Hispanic children. Social Science Research, 36, 767-788. http://dx.doi.org/10.1016/j.ssresearch.2006.04.002

Stanton-Salazar, R. D., \& S. U. Spino. (2001). The network orientations of highly resilient urban minority youth: A network-analytic account of minority socialization and its educational implications. Urban Review, 32, 227-61. http://dx.doi.org/10.1023/A:1005122211864

Teachman, J., Paasch, K., \& Carver, K. (1996). Social capital and dropping out of school early. Journal of Marriage and the Family, 58, 773-784. http://dx.doi.org/10.2307/353735

Tillman, K.H., Guo, G., \& Harris, K.M. (2006). Grade retention among immigrant children. Social Science Research, 35(1), 129-156. http://dx.doi.org/10.1016/j.ssresearch.2004.07.001

White, M. J., \& Glick, J. E. (2000). Generation status, social capital and the routes out of high school. Sociological Forum, 15(4), 671-691. http://dx.doi.org/10.1023/A:1007515100190

Witkow, M. R., \& Fuligni, A. J. (2007). Achievement goals and daily school experiences among adolescents with Asian, Latino, and European American backgrounds. Journal of Educational Psychology, 99, 584-596. http://dx.doi.org/10.1037/0022-0663.99.3.584

\section{Notes}

Note 1. In this paper, immigrant youth is defined as youth who have at least one immigrant parent.

Note 2. Although respondents were allowed to nominate 5 best friends, roughly two thirds of respondents nominated only one friend. This introduced a significant bias of the sample estimate of the network size. Consequently, network size is not used as an independent measure in this study.

Note 3. Regression models where generation 1.5 was used as a reference category (not shown) confirm that this generation ranks first among other immigrant youths with regard to educational achievement and attainment.

Note 4. The effect of prior achievement (Wave I) on attainment (Wave III) is strongly positive and significant in all regression models.

Note 5. I found a statistically significant effect of peer network heterogeneity on academic attainment of immigrant youths but no effect on achievement.

Note 6. From the analyses just presented it can be inferred that educational outcomes of generation 2.5 approximate those of native youth. 
Table 1. Descriptive statistics of study variables

\begin{tabular}{|c|c|c|c|c|}
\hline $\mathrm{N}=14,322$ & Weighted Mean & St. Dev. & Min & Max \\
\hline \multicolumn{5}{|l|}{ Dependent Variables } \\
\hline Educational Achievement & 2.82 & 0.76 & 0.77 & 4.00 \\
\hline Educational Attainment & 0.54 & 0.51 & 0.00 & 1.00 \\
\hline \multicolumn{5}{|l|}{ Peer social capital } \\
\hline Network GPA & 2.80 & 0.49 & 0.89 & 3.96 \\
\hline Network Density & 0.31 & 0.09 & 0.12 & 0.87 \\
\hline Network Heterogeneity & 0.24 & 0.18 & 0.04 & 0.92 \\
\hline \multicolumn{5}{|l|}{ School-Level Controls } \\
\hline Private School & 0.19 & 0.42 & 0.00 & 1.00 \\
\hline Average SES ${ }^{1}$ & 0.35 & 0.10 & 0.12 & 0.72 \\
\hline Percentage of Immigrant Youths ${ }^{1}$ & 0.13 & 0.15 & 0.00 & 0.56 \\
\hline \multicolumn{5}{|l|}{ Immigrant Generational Status } \\
\hline Generation 1 & 0.07 & 0.12 & 0.00 & 1.00 \\
\hline Generation 1.5 & 0.04 & 0.08 & 0.00 & 1.00 \\
\hline Generation 2 & 0.13 & 0.23 & 0.00 & 1.00 \\
\hline Generation 2.5 & 0.08 & 0.14 & 0.00 & 1.00 \\
\hline Generation 3.0 & 0.67 & 0.56 & 0.00 & 1.00 \\
\hline \multicolumn{5}{|l|}{ Individual-Level Controls } \\
\hline African-American & 0.16 & 0.36 & 0.00 & 1.00 \\
\hline Asian & 0.05 & 0.23 & 0.00 & 1.00 \\
\hline Hispanic & 0.14 & 0.35 & 0.00 & 1.00 \\
\hline Non-Hispanic White & 0.65 & 0.45 & 0.00 & 1.00 \\
\hline Family Income $^{1}$ & 5.22 & 1.42 & 0.26 & 14.21 \\
\hline Parents' Education & 5.37 & 2.36 & 0.00 & 10.85 \\
\hline Parents' Occupational Prestige & 1.88 & 1.09 & 0.03 & 5.08 \\
\hline Age & 15.46 & 1.81 & 11.00 & 21.00 \\
\hline Male & 0.50 & 0.48 & 0.00 & 1.00 \\
\hline \multicolumn{5}{|l|}{ Family Social Capital } \\
\hline Two-Parent Household & 0.57 & 0.16 & 0.00 & 1.00 \\
\hline Single-Parent Household & 0.23 & 0.41 & 0.00 & 1.00 \\
\hline Non-Parent Household & 0.18 & 0.37 & 0.00 & 1.00 \\
\hline Number of Siblings & 0.23 & 0.36 & 0.00 & 1.00 \\
\hline Parents' Educational Expectations & 4.36 & 0.87 & 1.00 & 6.58 \\
\hline Parent-Child Interactions & 0.41 & 0.29 & 0.01 & 1.66 \\
\hline Family Social Support & 4.00 & 1.29 & 0.95 & 5.67 \\
\hline
\end{tabular}

These variables were transformed by the Box-Cox method in order to satisfy the multilevel normality condition of HLM (see more on HLM in Raudenbush \& Bryk, 2002). 
Table 2. HLM regression models of school- and level predictors of educational achievement

\begin{tabular}{|c|c|c|c|c|c|c|}
\hline \multirow{3}{*}{\begin{tabular}{|l} 
\\
Immigrant Generation Status $^{\mathrm{A}}$
\end{tabular}} & \multicolumn{6}{|c|}{ Models } \\
\hline & \multirow[t]{2}{*}{1} & \multirow[t]{2}{*}{2} & \multirow[t]{2}{*}{3} & \multirow[t]{2}{*}{4} & \multirow[t]{2}{*}{5} & \multirow[t]{2}{*}{6} \\
\hline & & & & & & \\
\hline Generation $1^{\text {a }}$ & $0.11 * * *$ & $0.09 * * *$ & $0.06^{* * *}$ & $0.04 *$ & $0.06^{* * *}$ & $0.06^{* * *}$ \\
\hline Generation $1.5^{\mathrm{a}}$ & $0.07 * * *$ & $0.10^{* * *}$ & $0.11^{* * *}$ & $0.07 * * *$ & $0.10^{* * *}$ & $0.10 * * *$ \\
\hline Generation $2^{\mathrm{a}}$ & 0.03 & $0.07 * * *$ & $0.05^{* * *}$ & $0.04 *$ & $0.05^{*}$ & $0.06^{* * *}$ \\
\hline Generation $2.5^{\mathrm{a}}$ & $-0.06^{*}$ & -0.03 & -0.01 & 0.03 & 0.01 & -0.01 \\
\hline \multicolumn{7}{|l|}{ School-Level Controls ${ }^{B}$} \\
\hline Private School & & $0.30 * *$ & $0.28^{* * *}$ & 0.10 & $0.21 * * *$ & $0.24 * * *$ \\
\hline Average SES & & 0.02 & 0.01 & $0.11 *$ & 0.04 & 0.03 \\
\hline Percentage of Immigrant Youth & & -0.01 & -0.00 & 0.01 & -0.01 & -0.04 \\
\hline \multicolumn{7}{|l|}{ Individual-Level Controls ${ }^{\mathrm{A}}$} \\
\hline African-American ${ }^{\mathrm{b}}$ & & $-0.15 * * *$ & $-0.10 * * *$ & $-0.11 * * *$ & $-0.13 * * *$ & $-0.11 * * *$ \\
\hline Asian $^{\mathrm{b}}$ & & 0.01 & 0.04 & 0.02 & 0.02 & 0.06 \\
\hline Hispanic $^{\mathrm{b}}$ & & $-0.22 * * *$ & $-0.13 * * *$ & $-0.14 * * *$ & $-0.17 * * *$ & $-0.17 * * *$ \\
\hline Family Income & & $0.11^{* * *}$ & $0.08^{* * *}$ & $0.06 * * *$ & $0.07 * * *$ & $0.07 * * *$ \\
\hline Parents' Education & & $0.07 * * *$ & $0.04 * *$ & 0.02 & $0.03 * *$ & $0.04 * *$ \\
\hline Parents' Occupational Prestige & & 0.02 & 0.02 & 0.01 & 0.01 & 0.02 \\
\hline Age & & $-0.10 * * *$ & $-0.04 * *$ & -0.02 & $-0.05^{* *}$ & $-0.04 * *$ \\
\hline Male $^{c}$ & & $0.24 * * *$ & $0.17 * * *$ & $0.12 *$ & $0.16^{*}$ & $0.16^{* * *}$ \\
\hline \multicolumn{7}{|l|}{ Family Social Capital $^{\mathrm{A}}$} \\
\hline Single-Parent Household ${ }^{\mathrm{d}}$ & & & $-0.10 * * *$ & $-0.06 * * *$ & $-0.06 * * *$ & $-0.08 * * *$ \\
\hline Non-Parent Household ${ }^{\mathrm{d}}$ & & & -0.02 & $0.05^{*}$ & 0.04 & 0.03 \\
\hline Number of Siblings & & & $-0.11 * * *$ & $-0.16^{* * *}$ & -0.07 & $-0.09^{*}$ \\
\hline Parents' Educational Expectations & & & $0.16^{* * *}$ & $0.11 *$ & $0.16^{* * *}$ & $0.16^{* * *}$ \\
\hline Parent-Child Interactions & & & 0.02 & 0.02 & 0.03 & -0.00 \\
\hline Family Social Support & & & -0.06 & -0.06 & -0.04 & -0.03 \\
\hline \multicolumn{7}{|l|}{ Peer Social Capital ${ }^{\text {B }}$} \\
\hline Network GPA & & & & $0.41^{* * *}$ & & \\
\hline Network Density & & & & & -0.01 & \\
\hline Network Heterogeneity & & & & & & -0.03 \\
\hline Constant $^{\mathrm{A}}$ & $2.95 * * *$ & $3.01 * * *$ & $2.94^{* * *}$ & $2.32^{* * *}$ & $2.90 * * *$ & $2.95^{* * *}$ \\
\hline Model Comparison Test (df) & & $1,135 * * *$ & $379 * *$ & $160^{* * *}$ & 49 & 88 \\
\hline models compared & & 1 and 2 & 2 and 3 & 4 and 3 & 5 and 3 & 6 and 3 \\
\hline
\end{tabular}

Note: $1 .{ }^{* * *} \mathrm{p}<0.001 ;{ }^{* *} \mathrm{p}<0.01 ;{ }^{*} \mathrm{p}<0.05$.

2. A - individual-level indicators; B - school-level indicators.

3. Reference Categories: a - generation 3+ (i.e., native-parentage adolescents); $\mathrm{b}-$ non-Hispanic white; $\mathrm{c}-$ female; $\mathrm{d}$ - two-parent household; $\mathrm{c}$ - household of up to four residents; $\mathrm{e}$ - native-parentage adolescents. 
Table 3. HLM regression coefficients of school- and level predictors of educational attainment

\begin{tabular}{|c|c|c|c|c|c|c|}
\hline \multirow{3}{*}{ Immigrant Generation Status $^{\mathrm{A}}$} & \multicolumn{6}{|c|}{ Models } \\
\hline & \multirow[t]{2}{*}{1} & \multirow[t]{2}{*}{2} & \multirow[t]{2}{*}{3} & \multirow[t]{2}{*}{4} & \multirow[t]{2}{*}{5} & \multirow[t]{2}{*}{6} \\
\hline & & & & & & \\
\hline Generation $1^{\text {a }}$ & -0.06 & $0.93 * * *$ & $0.85 * * *$ & $0.47 * *$ & $0.74 * * *$ & $0.62 * * *$ \\
\hline Generation $1.5^{\mathrm{a}}$ & $0.34 * * *$ & $1.10 * * *$ & $1.03 * * *$ & $0.96 * * *$ & $1.02 * * *$ & $1.21 * * *$ \\
\hline Generation $2^{\mathrm{a}}$ & 0.04 & $0.57 * * *$ & $0.51 *$ & $0.42 *$ & $0.41 *$ & $0.49 * *$ \\
\hline Generation $2.5^{\mathrm{a}}$ & -0.10 & -0.22 & -0.12 & -0.09 & -0.07 & -0.12 \\
\hline \multicolumn{7}{|l|}{ School-Level Controls ${ }^{\text {B }}$} \\
\hline Private School & & $0.52 * * *$ & $0.39 * * *$ & 0.13 & $0.26 * * *$ & $0.33 * * *$ \\
\hline Average SES & & -0.07 & -0.02 & 0.08 & 0.04 & 0.05 \\
\hline Percentage of Immigrant Youth & & $-0.26 *$ & -0.10 & -0.06 & -0.10 & -0.10 \\
\hline \multicolumn{7}{|l|}{ Individual-Level Controls ${ }^{\mathrm{A}}$} \\
\hline African-American ${ }^{\mathrm{b}}$ & & $-0.45 * * *$ & $-0.38 * * *$ & -0.11 & -0.19 & $-0.23 *$ \\
\hline$A \operatorname{sian}^{\mathrm{b}}$ & & $0.41 * * *$ & $0.45 * * *$ & $0.32 *$ & $0.37 * *$ & $0.36 * * *$ \\
\hline Hispanic $^{\mathrm{b}}$ & & $-0.61 * * *$ & $-0.54 * * *$ & $-0.36+$ & $-0.52 * * *$ & $-0.55 * * *$ \\
\hline Family Income & & $0.31 * * *$ & $0.26 * * *$ & $0.19 * * *$ & $0.23 * * *$ & $0.25 * * *$ \\
\hline Parents' Education & & $0.19 * *$ & $0.18 * *$ & 0.10 & $0.18 * *$ & $0.15 * *$ \\
\hline Parents' Occupational Prestige & & $0.21 * *$ & $0.19 *$ & $0.14^{+}$ & 0.09 & 0.17 \\
\hline Age & & -0.21 & -0.12 & -0.08 & -0.10 & -0.10 \\
\hline Male $^{c}$ & & $0.55 * * *$ & $0.42 * * *$ & $0.31 * * *$ & $0.26 * * *$ & $0.47 * * *$ \\
\hline Ed. Achievement (Wave I) & & $2.76 * * *$ & $2.40 * * *$ & $1.51 * * *$ & $1.67 * * *$ & $1.68 * * *$ \\
\hline \multicolumn{7}{|l|}{ Family Social Capital $^{\mathrm{A}}$} \\
\hline Single-Parent Household ${ }^{\mathrm{d}}$ & & & $-0.31 * * *$ & $-0.22 * * *$ & $-0.32 * * *$ & $-0.35 * * *$ \\
\hline Non-Parent Household ${ }^{\mathrm{d}}$ & & & $-0.33 * * *$ & $-0.29 * * *$ & $-0.35 * * *$ & $-0.28 * * *$ \\
\hline Number of Siblings & & & $-0.11+$ & -0.02 & -0.02 & -0.10 \\
\hline Parents' Educational Expectations & & & $0.23 * * *$ & $0.24 * * *$ & $0.21 * * *$ & $0.25 * * *$ \\
\hline Parent-Child Interactions & & & $0.22 * * *$ & $0.12 *$ & $0.21 * * *$ & $0.26 * * *$ \\
\hline Family Social Support & & & $0.60 * *$ & $0.56 * *$ & $0.31 * *$ & $0.39 *$ \\
\hline \multicolumn{7}{|l|}{ Peer Social Capital $^{\text {B }}$} \\
\hline Network GPA & & & & $0.69 * * *$ & & \\
\hline Network Density & & & & & -0.01 & \\
\hline Network Heterogeneity & & & & & & -0.14 \\
\hline Constant $^{\mathrm{A}}$ & $-0.87 * * *$ & $-4.07 * * *$ & $-6.98 * * *$ & $-7.53 * * *$ & $-8.22 * * *$ & $11.06 * * *$ \\
\hline Model Comparison Test (df) & & $1,709 * * *$ & $812 * * *$ & $315 * * *$ & 25 & 84 \\
\hline models compared & & 1 and 2 & 2 and 3 & 4 and 3 & 5 and 3 & 6 and 3 \\
\hline
\end{tabular}

Note: $1 .{ }^{* * *} \mathrm{p}<0.001 ;{ }^{* *} \mathrm{p}<0.01 ;{ }^{*} \mathrm{p}<0.05 ;{ }^{+} \mathrm{p}<0.1$.

2. A - individual-level indicators; $\mathrm{B}$ - school-level indicators.

3. Reference Categories: a - generation 3+ (i.e., native-parentage adolescents); b - non-Hispanic white; c female; $\mathrm{d}$ - two-parent household; $\mathrm{c}$ - household of up to four residents; $\mathrm{e}$ - native-parentage adolescents. 
Table 4. HLM regression coefficients of peer social capital factors, nativity status and their interactions

\begin{tabular}{|c|c|c|c|c|}
\hline & \multicolumn{4}{|c|}{ Models } \\
\hline & \multicolumn{2}{|c|}{ Educational Achievement } & \multicolumn{2}{|c|}{ Educational Attainment } \\
\hline & 1 & 2 & 1 & 2 \\
\hline \multicolumn{5}{|c|}{ Part A. Interaction Effect of Immigrant Generational Status and Network GPA } \\
\hline \multicolumn{5}{|l|}{ Peer Social Capital } \\
\hline Network GPA & $0.32 * * *$ & $0.44 * * *$ & $0.70 * * *$ & $0.65 * * *$ \\
\hline \multicolumn{5}{|l|}{ Immigrant Generation Status } \\
\hline Generations $1-2.5^{\mathrm{a}}$ & $0.08 * * *$ & 0.00 & $0.41 *$ & 0.03 \\
\hline \multicolumn{5}{|c|}{ Interactions of Immigrant Generation Status and Network GPA } \\
\hline Generations $1-2.5^{\mathrm{a}}$ & & $0.20 * * *$ & & $0.93 * * *$ \\
\hline \multicolumn{5}{|c|}{ Part B. Interaction Effect of Immigrant Generational Status and Network Density } \\
\hline \multicolumn{5}{|l|}{ Peer Social Capital } \\
\hline Network Density & 0.02 & -0.08 & 0.06 & -0.12 \\
\hline \multicolumn{5}{|l|}{ Immigrant Generation Status } \\
\hline Generations $1-2.5^{\mathrm{a}}$ & $0.06^{*}$ & -0.01 & $0.39 * * *$ & $0.21 *$ \\
\hline \multicolumn{5}{|c|}{ Interactions of Immigrant Generation Status and Network Density } \\
\hline Generations $1-2.5^{\text {a }}$ & & $0.22 *$ & & $0.48 *$ \\
\hline \multicolumn{5}{|c|}{ Part A. Interaction Effect of Immigrant Generational Status and Network Heterogeneity } \\
\hline \multicolumn{5}{|l|}{ Peer Social Capital } \\
\hline Network Heterogeneity & -0.01 & 0.05 & -0.11 & -0.05 \\
\hline \multicolumn{5}{|l|}{ Immigrant Generation Status } \\
\hline Generations $1-2.5^{\mathrm{a}}$ & $0.09 * * *$ & $0.06^{* * *}$ & $0.54 * * *$ & $0.61 *$ \\
\hline \multicolumn{5}{|c|}{ Interaction of Immigrant Generation Status and Network Heterogeneity } \\
\hline Network Heterogeneity & & -0.06 & & $-0.18^{*}$ \\
\hline
\end{tabular}

Note: $1 .{ }^{* * *} \mathrm{p}<0.001 ;{ }^{* *} \mathrm{p}<0.01 ;{ }^{*} \mathrm{p}<0.05 .2$. Dependent variables are educational achievement (Wave I) and educational attainment (Wave III). 3. Regression coefficients of the control variables are not shown for the sake of the space. 4. Reference Categories: a-generation 3+ (i.e., native-parentage adolescents). 